\title{
SELF-EFFICACY AND PRIOR ICT EXPERIENCE: EFFECTS OF INDIVIDUAL DIFFERENCES ON SCIENCE TEACHERS' ACCEPTANCE OF DIGITAL VIDEOS IN ZIMBABWE
}

\author{
Norman Karimazondo \\ Department of Geography \\ ${ }^{1}$ Bindura University of Science Education P. Bag 1020, Bindura, Zimbabwe \\ Jérémy Castéra \\ Department of Educational Technologies \\ Aix-Marseille Université, EA4671 ADEF, ENS de Lyon, Aix-Marseille, France \\ Maria Antonietta Impedovo \\ School of Education \\ Aix-Marseille Université, EA4671 ADEF, ENS de Lyon, Aix-Marseille, France \\ Lawrence Mango \\ Department of Geography \\ Bindura University of Science Education, P. Bag 1020, Bindura, Zimbabwe
}

\begin{abstract}
Information and Communication Technology (ICT) is yet to penetrate Zimbabwean schools. However, several programs in 2009 and 2011 tried to promote the teaching and learning of science and mathematics in schools through new technologies. Based on the Technology Acceptance Model (TAM), the study aims to assess the effect of technology self-efficacy and prior ICT experience on Zimbabwean in-service science teachers' acceptance of digital videos in science education as required by the demands of the updated curriculum. Quantitative analysis was used to gather data from sixty-three Zimbabwean in-service science teachers. The study has shown a positive effect on the perceptions of the TAM on both technology self-efficacy and prior ICT experience. The study recommends teacher training in the use of ICT, particularly digital videos for the effective teaching and learning process.
\end{abstract}

Keywords: Digital videos, Information communication technology, Self-efficacy, In-service teachers, Technology Acceptance Model

\section{INTRODUCTION}

The rapid advancement in Information and Communication Technology (ICT) is revolutionizing teaching and learning of science subjects [9]. In science education, ICT teaching activities include tutorial applications, simulations, modelling and use of multimedia for example digital videos and use of the internet to access information [4]. This study focuses on digital videos which are part of e-learning multimedia components for teachers and students to access digital content in the Zimbabwean context.

Especially, the research was done regarding the trends of science education in Zimbabwe. A study by Kusure and Basira noted a decline in enrolment of science students in Zimbabwe; poor pass rates in science every year, and under-supply of appropriately qualified science teachers [7]. Their study revealed that the Zimbabwean government has responded by rolling out e-learning programmes to promote science education. To date, more than eight hundred and sixty schools across the country had received elearning equipment [7]. The same study highlighted 
that the use of interactive ICTs such as digital videos and other technological equipment has been found to reduce perceived difficulties in learning and increase motivation for the learning of science subjects. Other benefits for using digital videos include enhancing student comprehension, remembering of content, and provision of diverse learning styles [10].

Some of the evidence suggests that they are problems in trying to promote e-learning. A survey of the schools in Mashonaland West Province in the mid-2011 showed that most of the e-learning equipment was not being utilized [11]. Paradoxically, the science syllabus aims to promote the use of ICT as an aid to experiments and as a tool for interpretation of experimental and theoretical results [2]. Although, the science syllabus demands the teachers to use digital videos in teaching science on the other hand it's quite new technology in Zimbabwe, teachers are likely to resist and threatened by its presence.

Researchers and other stakeholders in education expect science teachers to use digital videos in ways which are consistent with the belief that new technology will impact on teaching and learning of science. Teachers are faced with many variables that interact with each other to facilitate the acceptance of computer related technology $[3 ; 13]$. This has raised some questions to what causes individual science teachers in Zimbabwe to accept new ICTs like digital videos in science education. Is it something inherent in the individual science teachers? Therefore, this study aims to look at the effects of individual differences on Zimbabwean science teachers' acceptance of digital videos in science education.

\section{METHODS AND MATERIALS}

\section{A. Research Design}

The research used a convenient sample of sixty-three Zimbabwean in-service science teachers of both gender categories. The sample consisted of thirty-two females and thirty-one males aged between twentyone and sixty-two. Participants who volunteered for the study were drawn from eleven secondary schools in Marondera District, Mashonaland East Province. To contact the participants in their schools the researchers sought permission from the regional authorities to carry out the research. After being granted the research permission the researchers visited the participants in their various schools.

\section{B. Instrument}

A questionnaire was designed to study the effect of prior ICT experience and technology self-efficacy on in-service science teachers' acceptance of digital videos in the teaching of science subjects. The questionnaire consisted of twenty randomly mixed items addressing variables which include prior ICT experience, technology self-efficacy, perceived ease of use, and perceived usefulness as shown in Table 1. Individual differences which are external to the TAM were measured with items on prior ICT experience, technology self-efficacy whereas items on perceived ease of use, and perceived usefulness measured perceptions which are internal to the TAM.

The items for the variables were adapted from previous studies of the TAM to ensure content validity and modified to meet the specific demands of the research project. Perceived ease of use and perceived usefulness was measured using items from prior research by Kim et al., whereas items about technology self-efficacy and prior ICT experience were adapted from research by Bourgonjon et al.; Lamb et al. $[1 ; 6 ; 8]$. All items are based on a five point Likert scale, ranging from one (strongly disagree) to five (strongly agree). A pilot study was done with fifty pre-service science teachers at Bindura University of Science Education to assess the validity of the instrument. All items were found to be valid.

Table 1: Items related Prior ICT Experience (PICTE), Technology Self-efficacy (TSE), Perceived Ease of Use (PEU) and Perceived Usefulness (PU).

\begin{tabular}{|l|l|}
\hline PICTE_3. & I rarely play digital videos in science lessons. \\
\hline PICTE_9. & I have never used digital videos in science lessons. \\
\hline PICTE_11. & I have played different types of digital videos in my science lessons. \\
\hline PICTE_17. & I would describe myself as experienced in using computers, internet and projectors. \\
\hline PICTE_20. & I often play digital videos in science lessons using a computer and projector. \\
\hline TSE_5. & I would understand how to use videos in science lessons. \\
\hline TSE_7. & I would navigate freely on internet for digital videos to use in a science lessons. \\
\hline
\end{tabular}




\begin{tabular}{|l|l|}
\hline TSE_12. & I am confident that I would be able to use digital videos in science lessons. \\
\hline TSE_14. & I would be competent on using digital videos in science lessons. \\
\hline TSE_19. & I would overcome obstacles that occur when I use the digital videos in science lessons. \\
\hline PEU_2. & Learning to use digital videos would be easy for me. \\
\hline PEU_10. & I would find it easy to operate features of digital videos during science lessons. \\
\hline PEU_15. & I would find it easy to get the digital videos to do what I want it to do. \\
\hline PEU_16. & Interacting with digital videos during lessons would be easy for me. \\
\hline PEU_18. & I would find the digital videos to be easy to use. \\
\hline PE_1. & Using digital videos would improve my performance in teaching science. \\
\hline PU_4. & I think digital videos would help my students to understand science. \\
\hline PU_6. & Using digital videos would enhance effectiveness in my work. \\
\hline PU_8. & I would find digital videos useful in my work. \\
\hline PU_13. & Using digital videos would help me to explain abstract concepts in science. \\
\hline
\end{tabular}

\section{Data collection}

The researchers administered the questionnaire by visiting the respondents in their respective schools after seeking permission from the regional authorities. This was done during the second term school calendar over a period of two weeks. Research participants were invited to participate in the study and were provided with instructions for completing the task both in written and verbal form. According to the instructions in the written consent form, the participants were informed about the purpose of the study, confidentiality of their information, risks and benefits for participating in the study if they were available and their right to withdraw from the study at any time during and after the study. The data collected was analysed using
Pearson Correlation, multiple and linear regression analysis in SPSS V.21.

\section{RESULTS AND DISCUSSION}

\section{A. Relationships among the study variables}

The table 2 below shows correlation (r) matrix of the relationship among the study variables. All the correlations are significant and positive. Strong positive correlations were found between technology self-efficacy and perceived ease of use $(r=0.73)$ and technology self-efficacy and perceived usefulness ( $\mathrm{r}$ $=0.71$ ). Moderate positive correlations were found between perceived ease of use and perceived usefulness $(\mathrm{r}=0.54)$, prior ICT experience and perceived ease of use $(\mathrm{r}=0.46)$ and prior ICT experience and technology self-efficacy $(r=0.38)$. Weak positive correlations were found between prior ICT experience and perceived usefulness $(r=0.32)$.

Table 2: Pearson correlation coefficients among the study variables

\begin{tabular}{llcccc}
\hline & & PU & PEU & TSE & PICTE \\
\hline PU & Pearson Correlation & 1 & $.536^{* *}$ & $.713^{* *}$ & $.315^{* *}$ \\
& Sig. (1-tailed) & & .000 & .000 & .006 \\
& $\mathrm{~N}$ & 63 & 63 & 63 & 63 \\
\hline PEU & Pearson Correlation & $.536^{* *}$ & 1 & $.729^{* *}$ & $.461^{* * *}$ \\
& Sig. (1-tailed) & .000 & & .000 & .000 \\
& $\mathrm{~N}$ & 63 & 63 & 63 & 63 \\
\hline TSE & Pearson Correlation & $.713^{* *}$ & $.729^{* *}$ & 1 & $.383^{* *}$ \\
& Sig. (1-tailed) & .000 & .000 & & .001 \\
& $\mathrm{~N}$ & 63 & 63 & 63 & 63 \\
\hline PICTE & Pearson Correlation & $.315^{* *}$ & $.461^{* *}$ & $.383^{* *}$ & 1
\end{tabular}


Sig. (1-tailed)

$\mathrm{N}$

$$
.006
$$

63
.000

63
.001

63
63

**. Correlation is significant at the 0.01 level (1-tailed).

b. Variables: PU (Perceived Usefulness), PEU (Perceived Ease of Use, TSE (Technology Self-Efficacy, PICTE (Prior ICT Experience).

\section{B. Effects of the independent variables on dependent variables}

Table 3 shows a multiple regression analysis in which perceived usefulness was set as a dependent variable and, prior ICT experience and technology self-efficacy as independent variables. The results of the multiple regression indicated that the independent variables explain $51 \%$ of the total variance $(R=0.715, R$ Square $=0.511)$. Standardized regression coefficients $(\beta)$ indicated the relative effect of the independent variables and they are as follows: technology self-efficacy $(\beta=0.694)$ and prior ICT experience $(\beta=0.049)$.

Another multiple regression analysis was also conducted analysis in which perceived ease of use was set as a dependent variable and, prior ICT experience and technology self-efficacy as independent variables. Table 3 shows that the results of the multiple regression indicate that the independent variables explain $57 \%$ of the total variance $(R=0.755$, $R$ Square $=0.570)$. Standardized regression coefficients $(\beta)$ indicated the relative effect of the independent variables and they are as follows: technology self-efficacy $(\beta=0.648)$ and prior ICT experience $(\beta=0.212)$.

Lastly, a simple regression analysis was conducted in which technology self-efficacy was set as a dependent variable and prior ICT experience as an independent variable. Table 3 shows that the results of simple regression indicated that the independent variable explain $15 \%$ of the total variance $(R=0.383$, $R$ Square $=0.147)$. Standardized regression coefficients $(\beta)$ indicated that the relative effect of the independent variable, prior ICT experience as $(\beta=0.383)$.

Table 3: Results of regression on Perceived Usefulness, Perceived Ease of Use and Technology Self-Efficacy

\begin{tabular}{|c|c|c|c|c|c|c|c|c|}
\hline \multicolumn{2}{|c|}{ Model } & \multicolumn{2}{|c|}{$\begin{array}{l}\text { Unstandardized } \\
\text { Coefficients }\end{array}$} & $\begin{array}{l}\text { Standardized } \\
\text { Coefficients }\end{array}$ & \multirow[t]{2}{*}{$\mathrm{t}$} & \multirow[t]{2}{*}{ Sig } & \multirow[t]{2}{*}{$\mathrm{R}$} & \multirow[t]{2}{*}{$\mathrm{R}^{2}$} \\
\hline & & B & Std. Error & Beta $(\beta)$ & & & & \\
\hline \multirow[t]{3}{*}{$\overline{\mathrm{PU}}$} & Constant & 1.958 & .343 & - & 5.714 & .000 & .715 & .511 \\
\hline & TSE & .589 & .083 & .694 & 7.101 & .000 & & \\
\hline & PICTE & .043 & .085 & .049 & .500 & .619 & & \\
\hline \multirow[t]{3}{*}{ PEU } & Constant & .320 & .402 & - & .796 & .429 & .755 & .570 \\
\hline & TSE & .688 & .097 & .648 & 7.071 & .000 & & \\
\hline & PICTE & .232 & .100 & .212 & 2.317 & .024 & & \\
\hline \multirow[t]{2}{*}{ TSE } & Constant & 2.793 & .390 & - & 7.163 & .000 & .383 & .147 \\
\hline & PICTE & .394 & .122 & 383 & 3.242 & .002 & & \\
\hline
\end{tabular}

Dependent Variables: Perceived Usefulness (PU), Perceived Ease of Use (PEU) and Technology Self-Efficacy (TSE)

Predictors: Constant, Prior ICT Experience (PICTE), Technology Self-Efficacy (TSE)

According Thong, Hong, and Tam the effects of external variables on intention to use are mediated by perceptions [15]. Therefore this study was focused on investigating the effects of individual differences variables which are external to the TAM on perceived ease of use and perceived usefulness. Figure 1 shows a proposed model which is based on the findings of this research. 


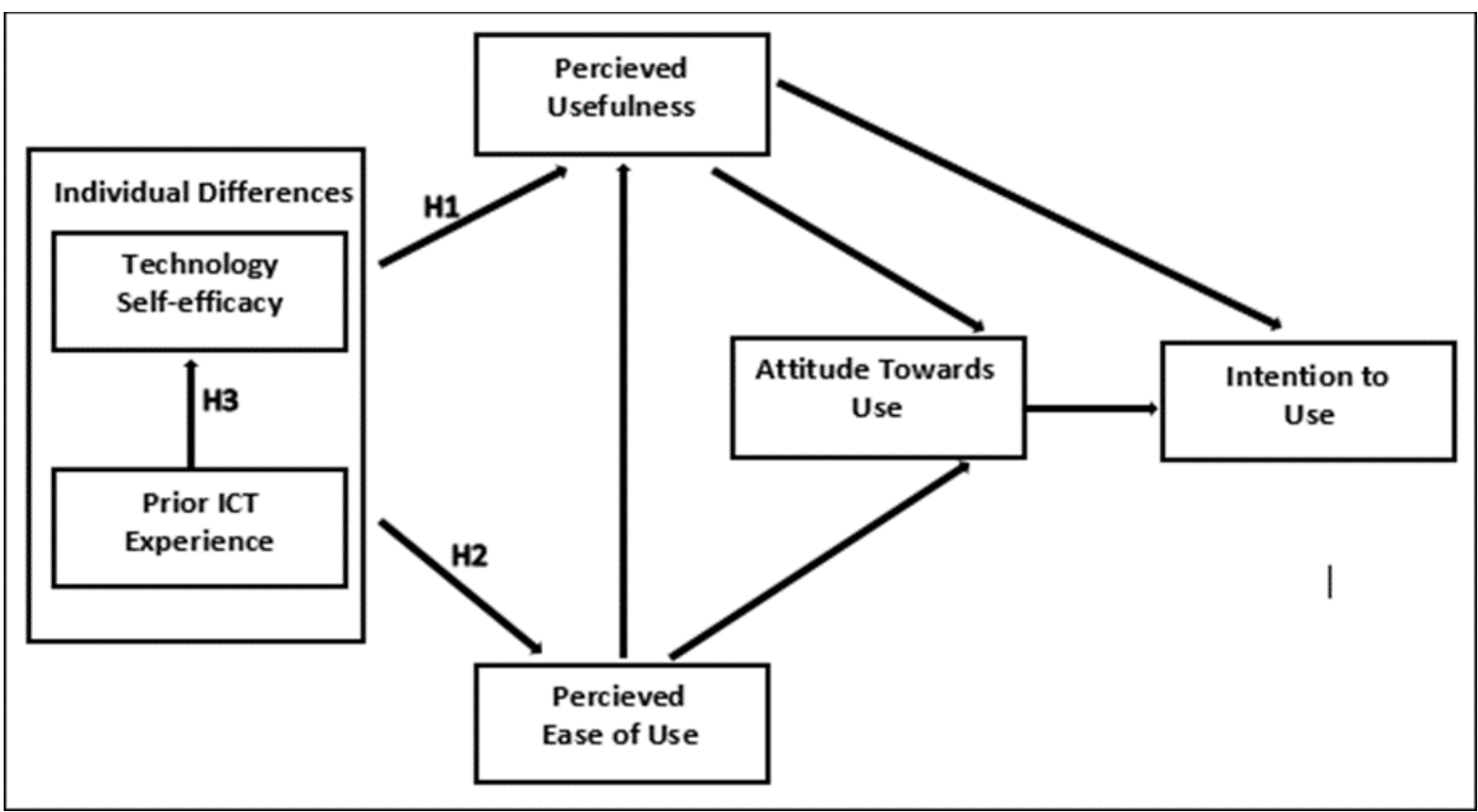

Figure 1: Proposed TAM based on research findings

Consistent with the hypothesis $(\mathrm{H} 3, \beta=$ 0.383 ) of the study, prior ICT experience has shown a positive effect on technology self-efficacy on the use of digital videos in science education. The level of experience in using technology influences to a considerable extent, an individual's technology selfefficacy [12]. Moreover, the study had proved that prior ICT experience has a positive effect on ease of use (H2, $\beta=0.212)$. This is congruent to a study by Bourgonjon et al., found out that high level of prior ICT experience has a profound effect on ease of use $(b=0.49, p<.001)[1]$. More ICT experience usually implies greater exposure to different types of applications and higher level of familiarity to various ICTs can help individual to learn how to use new technology more easily [15]. Therefore, higher level of ICT experience will lead to a higher level of perceived ease of use of digital videos in science education. In addition, prior ICT experience has a positive effect on perceived use of digital videos in science education ( $\mathrm{H} 1, \beta=0.05)$. This is in agreement with the results of a study by Bourgonjon et al., who also found out that prior ICT experience has an effect on perceived usefulness $(b=0.15, p<$ .001.) [1].

Consistent with hypothesis $(\mathrm{H} 2, \beta=0.648)$ of the study, technology self-efficacy has a positive effect on the ease of use of digital videos in science education. These results support prior research which has found that there is a direct relationship between technology self-efficacy and perceived ease of use [5; 15]. Users who have higher levels of confidence in

using ICT are more likely to find the digital technology easy to use [5]. Lastly, technology selfefficacy has a positive effect on perceived usefulness of digital videos in science education (H1, $\beta=0.694)$. In-service science teachers with a strong sense of technology self-efficacy will persist with their efforts and the result is that they are more likely to see digital videos being useful in their practice of teaching science [13].

This study contributes to the understanding of acceptance of digital videos in science education by demonstrating that Zimbabwean science teachers' individual differences have a positive effect on the perceptions of the TAM. All the effects of technology self-efficacy on perceptions are both strong and higher than that of prior ICT experience. Also, prior ICT experience has a positive effect towards technology self-efficacy in the use of digital videos in science education. When pre-service science teachers have experienced the affordances of technology in their learning at college, they would expect technology integration to continue over and over again $[13 ; 14]$.

The study has some limitations because of the small sample size of sixty-three in-service science teachers. Therefore, it is limited on how to detect 


\section{International Journal of Engineering Applied Sciences and Technology, 2020 \\ Vol. 4, Issue 9, ISSN No. 2455-2143, Pages 7-13 \\ Published Online January 2020 in IJEAST (http://www.ijeast.com)}

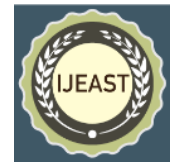

large differences between the measures of acceptance of digital videos in science education. Moreover, the use of perceptions rather than actual usage of digital videos in the study could have inflated the total variance explained by the study. This might give an overestimation of the study in terms of explaining the acceptance of digital videos in science education. Even though, perceived ease of use and perceived usefulness are constructs which have been reported to mediate all external variables to the TAM, there is a possibility that the effects may vary across different contexts and samples [13].

\section{CONCLUSIONS}

This study has several implications for science teachers and school administrators. Digital videos are not easy to use like emails, spreadsheets etc. for teachers with low levels of prior ICT experience and technology self-efficacy. They are quite involving and a lot of effort is required to search, censor, edit and integrate videos with other technologies. So there is need to enhance in-service science teachers with ICT background through training and staff development programs. Apart from this, the school administrators should provide access to a variety of technologies such as simulations, virtual labs, internet, iPads and computers to the science teachers. This is meant to develop the technology self-efficacy, which is linked to prior ICT experience in the use of digital videos in the teaching and learning process. This study recommends that future teachers should be provided with a course for Educational Technology that will enable them to integrate technology as part of their instructional strategies. Further studies can include an in-depth analysis of perceived usefulness of digital videos in science education.

\section{ACKNOWLEDGEMENTS}

Special thanks to all the science teachers in Marondera, Zimbabwe who provided data for the study. The authors would like to acknowledge the financial support from the ERASMUS MUNDUS STETTIN Action 2 program 2014-2015 for providing a scholarship to the corresponding author to study in Belgium and France respectively. In addition, the authors would like to thank Professor Timothy Teo for allowing us to use the Technology Acceptance Model.

\section{REFERENCES}

[1] Bourgonjon, J., Valcke, M., Soetaert, R., and Schellens, T. (2010). Students' perceptions about the use of video games in the classroom. Computers and Education, 54(4), 1145-1156.

[2] Chemistry - Advanced Level Syllabi - Zimbabwe Schools Examination Council. (2013, 201). Advanced Level Syllabi- Zimbabwe Schools Examination Council. Retrieved December 12, 2015, from http://www.zimsec.co.zw/resources/advancedlevel-syllabi.html

[3] Ferguson, R., Coughlan, T., Egelandsdal, K., Gaved, M., Herodotou, C., Hillaire, G., Jones, D., Jowers, I., Kukulska-Hulme, A., McAndrew, P., Misiejuk, K., Ness, I. J., Rienties, B., Scanlon, E., Sharples, M., Wasson, B., Weller, M. and Whitelock, D. (2019). Innovating Pedagogy 2019: Open University Innovation Report 7. Milton Keynes: The Open University.

[4] Hogarth, S., Bennett, J., Lubben, F., and Robinson, A. (2006). The effect of ICT teaching activities in science lessons on students' understanding of science ideas.

[5] Hong, W., Thong, J. Y., and Wai-Man Wong, K.Y. T. (2002). Determinants of user acceptance of digital libraries: An empirical examination of individual differences and system characteristics. Journal of Management Information Systems, 18(3), 97-124.

[6] Kim, Y. J., Chun, J. U., and Song, J. (2009). Investigating the role of attitude in technology acceptance from an attitude strength perspective. International Journal of Information Management, 29(1), 67-77.

[7] Kusure, L., and Basira, K. (2015). Proceedings of the First National Science and Mathematics Teachers Conference, Bindura University of Science Education, Bindura, Zimbabwe, 5-7 September, 2012.

[8] Lamb, R. L., Vallett, D., and Annetta, L. (2014). Development of a short-form measure of science and technology self-efficacy using rasch analysis. Journal of Science Education and Technology, 23(5), 641657.

[9] Liu, S.-H., Liao, H.-L., and Pratt, J. A. (2009). Impact of media richness and flow on e-learning technology acceptance. Computers \& Education, 52(3), 599-607.

[10] Mitra, B., Lewin-Jones, J., Barrett, H., and Williamson, S. (2010). The use of video to enable deep learning. Research in Post-Compulsory Education, 15(4), 405-414.

[11] Musiyandaka, D., Ranga, G., and Kiwa, J. F. (2013). An analysis of factors influencing success of ICT4D projects: a case study of the Schools Computerisation Programme in Mashonaland West 
Province, Zimbabwe. The Journal of Community Informatics, 9(4). Retrieved from http://www.cijournal.net/index.php/ciej/article/view/1016

[12] Paraskeva, F., Bouta, H., and Papagianni, A. (2008). Individual characteristics and computer selfefficacy in secondary education teachers to integrate technology in educational practice. Computers and Education, 50(3), 1084-1091.

[13] Teo, T. (2009). Modelling technology acceptance in education: A study of pre-service teachers. Computers \& Education, 52(2), 302-312.
[14] Teo, T., Faruk Ursavas, Ö., and Bahçekapili, E. (2011). Efficiency of the technology acceptance model to explain pre-service teachers' intention to use technology: A Turkish study. Campus-Wide Information Systems, 28(2), 93-101.

[15] Thong, J. Y., Hong, W., and Tam, K.-Y. (2002). Understanding user acceptance of digital libraries: what are the roles of interface characteristics, organizational context, and individual differences? International Journal of Human-Computer Studies, 57(3), 215-242. 